\title{
Paleoceanographic reconstruction of the Mozambique Channel : geochemical study of Fe-Mn crusts
}

\author{
Claire CHARLES ${ }^{1,2, *}$, Ewan PELLETER ${ }^{1}$, Sidonie \\ REVILLON $^{3}$, DIDIER BOURLES ${ }^{4}$, JEAN-MICHEL \\ KLUSKA $^{5}$, JEAN-ALIX BARRAT ${ }^{2}$
}

${ }^{1}$ IFREMER, Géosciences Marine, 29280 Plouzané, France ${ }^{2}$ CNRS, Univ Brest, UMR 6538, 29280 Plouzané, France ${ }^{3}$ SEDISOR/UMR 6538, 29280 Plouzané, France

${ }^{4}$ CNRS, UM 34 CEREGE, 13545 Aix-en-Provence, France

${ }^{5}$ TOTAL Exploration and Production, 64000 Pau, France (*correspondence: claire.charles@ifremer.fr)

The Mozambique Channel (MC) plays a key role in water mass exchange between the Atlantic and Indian Oceans. Today, Atlantic currents arrive from the south and are characterized by $\mathrm{Nd}$ isotope compositions $(\mathrm{ENd})$ between -9 and -11 , whereas Indian currents, resulting from the mixture between Atlantic and Pacific Ocean waters, flow from the north and are characterized by ENd between -8 and -7.5 [1]. Whereas recent studies [2] provide a good view of the present-day MC hydrodynamic conditions, the Cenozoic geodynamic history and its consequences on the topography and on the past deep-current circulation remains unclear.

Fe-Mn crusts represent archives of water-mass geochemistry [3]. Radiogenic isotope studies of these encrustations provide important information for the circulation patterns and/or geodynamic change reconstructions [4]. In this study, we focused on multi-elements and isotopic analyses of 9 thick Fe-Mn crusts, dredged over $2000 \mathrm{~km}$ in the MC, to investigate water mass changes during the Cenozoic.

The $E N d$ recorded by encrustations, based on a time scale built from radioactive decay of the authigenic ${ }^{10} \mathrm{Be} /{ }^{9} \mathrm{Be}$ ratio [5], show significant variability between the Indian and the Atlantic domains, most likely related to a major subsidence event near Bassas da India during the Pliocene and an uplift phenomenon of the Davie Ridge during the Middle-Miocene. This latter event suggests a deeper topography at EarlyMiocene and direct consequences on the Atlantic currents circulation.

The thesis of Claire CHARLES is co-funded by TOTAL and Ifremer as part of the PAMELA (Passive Margin Exploration Laboratories) project. [1] Jeandel et al. (1993) Earth Planet. Sci. Lett. 117, 581-591 [2] Collins et al. (2016) J. Geophys. Res. Oceans 121, 1291-1305 [3] Koschinsky and Halbach (1995) Geochim. Cosmochim. Acta 59, 5113-5132 [4] Frank et al. (2002) Paleoceanography 17, 121-129 [5] Bourlès et al. (1989) Geochim. Cosmochim. Acta 53, 443-452. 